\title{
Computed Tomography-Based Morphometric Analysis of Thoracic Pedicles: An Analysis of 1512 Pedicles and Their Correlation with Sex, Age, Weight and Height
}

\author{
Serdar DEMIROZ1', Sevki ERDEM² \\ ${ }^{1}$ Medicalpark Hospital, Department of Orthopaedics and Traumatology, Gebze, Turkey \\ ${ }^{2}$ Medicana Hospital, Department of Orthopaedics and Traumatology, Istanbul, Turkey \\ Corresponding author: Serdar DEMIROZ serdardemiroz@hotmail.com
}

\section{ABSTRACT}

AIM: To examine the morphological features of thoracic pedicles in a Turkish population.

MATERIAL and METHODS: This retrospective study was performed with the patients who were underwent thoracic CT for any reason such as trauma or pulmonary disorder. Patient's age, height, weight, and sex were recorded and pedicle length (PL), transverse pedicle diameter (TPD), sagittal pedicle diameter (SPD) and, transverse pedicle angle (TPA) were measured. The right and left pedicles were separately measured. The data obtained was analyzed and compared with other studies in the literature.

RESULTS: The highest mean TPA value was $33^{\circ}$ at T1, whereas the lowest mean TPA value was $3^{\circ}$ at T12. The highest mean PL value was $39.6 \mathrm{~mm}$ at T11, whereas the lowest mean PL value was $33.7 \mathrm{~mm}$ at T1. The lowest mean SPD value was $7.2 \mathrm{~mm}$, which was measured on T1, and the maximum mean SPD was $11.7 \mathrm{~mm}$ on T12. The minimum mean TPD value was $3.8 \mathrm{~mm}$ at T5 and the maximum value was $6.2 \mathrm{~mm}$ at T1. There was a statistically significant positive correlation between pedicle length and height in all vertebrae. Age had no effect on the morphological features of the thoracic pedicle. In males, PL, TPD, and SPD were higher than females.

CONCLUSION: Compared with other populations, the Turkish population has a smaller pedicle width on sagittal and transverse planes, and their PL and medial angling is similar to those of other populations. Male patients who are taller and overweight have higher pedicle width and length.

KEYWORDS: Thoracic pedicle, Morphometry, Pedicle angle, Pedicle diameter, Pedicle length

\section{INTRODUCTION}

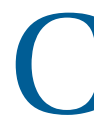
urrently, pedicle screw fixation is the most commonly used method for vertebral fixation. Pedicle screws are used in numerous cases that include tumors, trauma, infection, degenerative disorders, and deformities $(4,6)$. Compared with the previously used methods, such as hook-rod and cable fixation systems, pedicle screw fixation facilitates a more stable fixation in terms of biomechanics and results in a shorter duration the surgery. In deformity surgery, this method is applied on shorter segments and offers more effective recovery $(8,11)$. However, pedicle screw placement in the thoracic region is more challenging than that in the cervical and lumbar regions and is associated with higher rates of malposition because the pedicle is proximal to the neurovascular structures and the canal present at such locations is narrower $(14,23,24)$. Therefore, misplaced pedicle screws can result in serious neurological, vascular, and visceral complications. To prevent such complications, it is crucial to understand the morphological characteristics of pedicle.

The literature reveals that the morphometrical characteristics of vertebral pedicles vary by race $(10,15,24)$. Consequently, there are several studies that have focused on the pedicle characteristics in vertebrae in different countries $(12,26)$. In Turkey, there have been studies focusing on the morphological 
characteristics of cervical and lumbar vertebral pedicles; however, there studies focusing on the thoracic vertebral pedicles are limited $(7,19,20)$. To date, the study by Ugur et al. is the only study conducted in Turkey that examined the anatomical characteristics of thoracic vertebral pedicles and their association with the surrounding neural tissues on 20 cadavers; however, that study does not analyze transverse pedicle angle (TPA) and pedicle length (PL) and does not assess the effects of age, sex, height, and weight on the morphological characteristics of pedicles (22). The majority of the other studies available in the literature were conducted with small sample sizes (such as studies conducted with a sample size of 10), and most of these do not assess the effects of demographic characteristics such as age, sex, height, and weight on the morphological characteristics of pedicles (3). Moreover, most of these studies were conducted by using the measurements performed on cadaver specimens. Only a few studies have been conducted based on the CT measurements, which is the golden standard in preoperative planning $(9,13,26)$.

The present study aimed to analyze the morphological characteristics that are important for pedicle screw placement [PL, transverse pedicle diameter (TPD), sagittal pedicle diameter (SPD), and TPA] of thoracic vertebral pedicle as well as to determine the effects of sex, age, height, and weight on these parameters in the Turkish population. Considering that this is the first study in terms of its scope, we consider that the results of this study will help spinal surgeons in surgical planning.

\section{MATERIAL and METHODS}

This retrospective study was performed with the patients who were scheduled to undergo thoracic CT for any reason (trauma, pulmonary issues, etc.) at our hospital and was conducted for a period of 4 months by maintaining a record of the patient's age, height, weight, and sex after obtaining their informed consent at the time of their application for CT scan. The study included patients aged $\geq 18$ years; however, patients with vertebral deformities, such as scoliosis and kyphoses, as well as those with a recent or previous fractures caused by a trauma and those with congenital vertebral issues or containing an internal fixation material in their spine due to any reason were excluded, because the inclusion of such patients might cause miscalculations in measurements. A total of 1512 thoracic pedicles in 63 patients were analyzed. The characteristics of the right and left pedicles were separately measured, following which they were compared. Patients were divided into two groups - female and male-to study the effect of sex. The effects of height, weight, and age on pedicle characteristics were assessed using correlation analysis.

All CT scans were conducted using the same device (Toshiba Activion 16 CT scanner) with an interslice distance of $4 \mathrm{~mm}$ and the axial, sagittal, and coronal sections were obtained. PL, TPD, and TPA were measured on the axial plane termed the mid pedicle section, where two pedicles present the greatest width, whereas SPD was measured on the sagittal plane, where the pedicle exhibited the greatest width. All measurements were obtained in accordance with the instructions previously described in the literature using the Synapse Work station (Fujifilm Medical systems U.S.A., Inc.) and were performed by a single orthopedic surgeon who is experienced in vertebral surgery (to avoid interobserver inconsistency).

The lowest width of pedicle in the mid pedicle section was measured as the TPD. The pedicle entry point was considered as the point where the midline of the transverse process on the sagittal plane intersects with the lateral edge of the facet joint on the coronal plane. The angle between the upright line drawn toward TPD from the pedicle entry point and the vertical plane was considered asthe TPA. The length of the upright line drawn from the most flattened section of the posterior cortex of lamina to the TPD was considered as the PL (Figure 1A) (17). The narrowest section of the pedicle on the sagittal plane was considered as SPD (Figure 1B). The data obtained was analyzed and compared with other studies $(5,9,15,17-23)$.

\section{Statistical Analysis}

For the descriptive statistical data, mean, standard deviation, median minimum, maximum, frequency, and ratio values were used. Kolmogorov-Smirnov test was used to measure
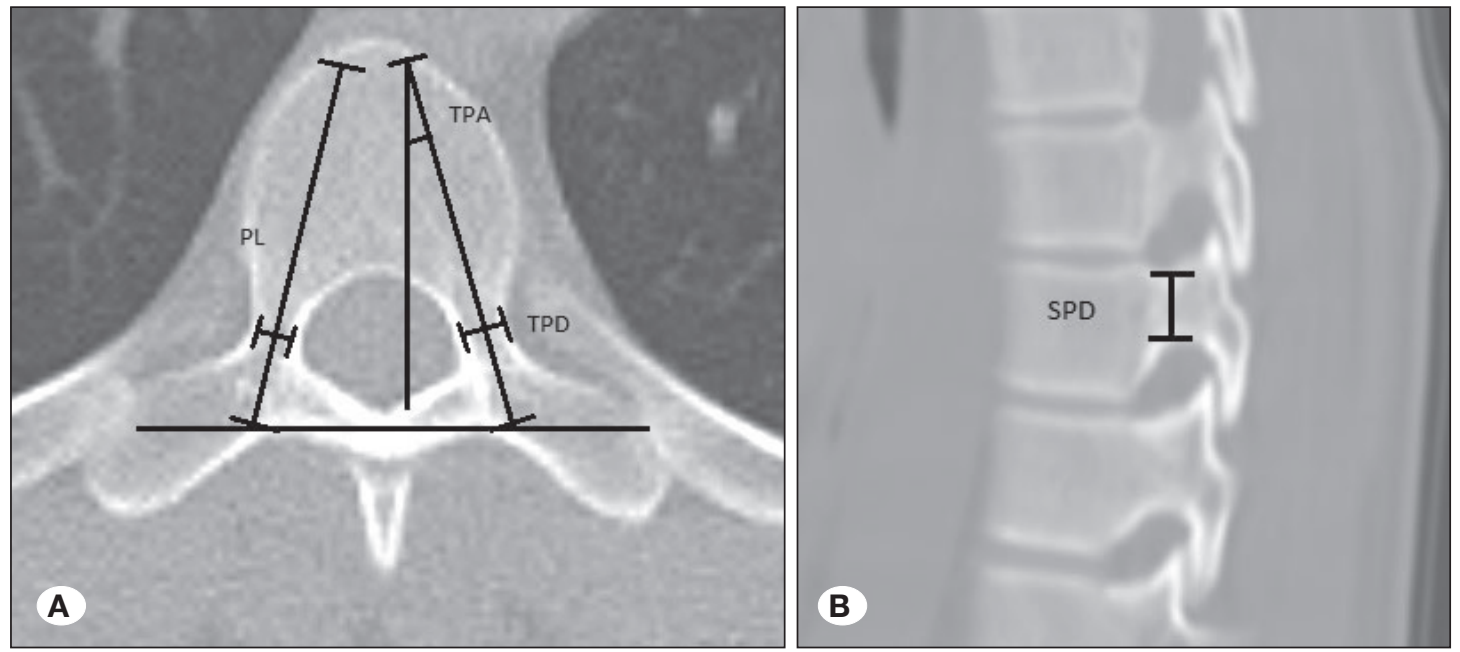

Figure 1:

A) Measurement of transverse pedicle diameter (TPD), pedicle length ( $P L)$ and transverse pedicle angle (TPA) in a mid pedicle section. B) Measurement of sagittal pedicle diameter. 
the distribution of variables. To analyze the quantitative independent data, unpaired sample $t$-test and Mann-Whitney $U$ test were used. To analyze the qualitative dependent data, paired sample $t$-test and Wilcoxon test were used. For correlation analysis, Spearman's correlation analysis was used. All analyses were conducted using SPSS 22.0 software.

\section{RESULTS}

The study included 63 patients (19 female and 44 male patients). The mean age was $40.7 \pm 10.7$ (range 18-60) years. The mean height and weight were $171.4 \pm 7.4$ (range 155-188) $\mathrm{cm}$ and $78.1 \pm 12.7$ (range 57-114) kg, respectively.

TPA values gradually decreased from $\mathrm{T} 1$ to the distal $\mathrm{T} 7$ vertebra, showing plateau values in T7-T9, following which it gradually decreased and attained the minimum value at T12. The highest mean TPA value was $33^{\circ}$ at $\mathrm{T} 1$, whereas the lowest mean TPA value was $3^{\circ}$ at T12. When the right and left pedicles were compared, it was observed that the TPA valueson the right side of the proximal T1-T2 and those on the right side of the distal T9-T12 were significantly higher than the left side (Table I).

PL values gradually increased from $\mathrm{T} 1$ to the distal T10, following which it decreased. The highest mean PL value was $39.6 \mathrm{~mm}$ at T11, where as the lowest mean PL value was 33.7 $\mathrm{mm}$ at T1. On comparing the right and left PL values, it was observed that the left PL values on all vertebrae, excluding T1 and T4, were significantly higher (Table II).

The lowest mean SPD value was $7.2 \mathrm{~mm}$, which was measured on $\mathrm{T} 1$, and this value gradually increased toward T12. The maximum mean SPD was $11.7 \mathrm{~mm}$ on T12. When the right

Table I: Results of Transverse Pedicle Angle and Comparison Between Right and Left Sides

\begin{tabular}{|c|c|c|c|c|}
\hline & Right & Left & \multirow{2}{*}{$\mathbf{p}$} & \\
\hline & Mean \pm SD & Mean \pm SD & & \\
\hline $\mathrm{T} 1$ & $34.3 \pm 6.1$ & $32.9 \pm 6.4$ & 0.023 & w \\
\hline T2 & $22.5 \pm 6.3$ & $21.2 \pm 5.6$ & 0.047 & w \\
\hline T3 & $14.3 \pm 5.0$ & $14.3 \pm 4.5$ & 0.808 & w \\
\hline T4 & $11.0 \pm 3.2$ & $10.8 \pm 2.8$ & 0.827 & w \\
\hline T5 & $10.0 \pm 2.8$ & $9.7 \pm 2.8$ & 0.867 & w \\
\hline T6 & $9.5 \pm 3.0$ & $9.1 \pm 2.4$ & 0.222 & w \\
\hline $\mathbf{T 7}$ & $8.2 \pm 2.2$ & $8.6 \pm 2.4$ & 0.229 & w \\
\hline T8 & $8.6 \pm 2.5$ & $8.5 \pm 2.8$ & 0.869 & w \\
\hline T9 & $8.5 \pm 2.2$ & $7.8 \pm 2.5$ & 0.014 & w \\
\hline $\mathrm{T} 10$ & $7.5 \pm 2.1$ & $6.8 \pm 2.2$ & 0.009 & w \\
\hline $\mathrm{T} 11$ & $5.0 \pm 1.7$ & $4.3 \pm 2.1$ & 0.007 & w \\
\hline $\mathrm{T} 12$ & $3.1 \pm 1.6$ & $2.5 \pm 1.9$ & 0.002 & w \\
\hline
\end{tabular}

wWilcoxon test, SD: Standard deviation. and left pedicles were compared, this value was observed to be significantly low only on the right T3 and T4. No significant difference was observed among the values of the remaining 10 vertebrae (Table III).

TPD gradually decreased from $\mathrm{T} 1$ to $\mathrm{T} 7$ and increased from

Table II: Results of Pedicle Length and Comparison Between Right and Left Sides

\begin{tabular}{|c|c|c|c|c|}
\hline & Right & Left & \multirow{2}{*}{$\mathbf{p}$} & \\
\hline & Mean \pm SD & Mean \pm SD & & \\
\hline $\mathbf{T 1}$ & $33.9 \pm 3.4$ & $33.5 \pm 3.6$ & 0.051 & $\mathrm{E}$ \\
\hline T2 & $35.6 \pm 3.9$ & $35.0 \pm 3.8$ & 0.019 & E \\
\hline T3 & $36.0 \pm 3.4$ & $35.5 \pm 3.6$ & 0.007 & $\mathrm{E}$ \\
\hline T4 & $36.1 \pm 3.5$ & $36.0 \pm 3.4$ & 0.703 & $\mathrm{E}$ \\
\hline T5 & $37.3 \pm 3.0$ & $37.0 \pm 3.0$ & 0.034 & $\mathrm{E}$ \\
\hline T6 & $38.0 \pm 2.9$ & $37.1 \pm 3.2$ & 0.000 & E \\
\hline $\mathrm{T7}$ & $38.8 \pm 2.8$ & $37.9 \pm 3.0$ & 0.000 & $\mathrm{E}$ \\
\hline T8 & $40.0 \pm 2.9$ & $39.1 \pm 2.8$ & 0.000 & $\mathrm{E}$ \\
\hline $\mathrm{T} 9$ & $40.5 \pm 3.2$ & $39.2 \pm 3.1$ & 0.000 & $\mathrm{E}$ \\
\hline $\mathrm{T} 10$ & $40.3 \pm 3.2$ & $39.5 \pm 3.3$ & 0.001 & E \\
\hline $\mathrm{T} 11$ & $40.0 \pm 3.3$ & $38.9 \pm 3.2$ & 0.000 & E \\
\hline $\mathrm{T} 12$ & $39.5 \pm 3.4$ & $38.5 \pm 3.3$ & 0.000 & E \\
\hline
\end{tabular}

${ }^{E}$ Paired sample $t$ test, SD: Standard deviation.

Table III: Results of Sagittal Pedicle Diameter and Comparison Between Right and Left Sides

\begin{tabular}{|c|c|c|c|c|}
\hline & Right & Left & \multirow{2}{*}{$\mathbf{p}$} & \\
\hline & Mean \pm SD & Mean \pm SD & & \\
\hline T1 & $7.2 \pm 0.8$ & $7.2 \pm 1.0$ & 0.837 & w \\
\hline T2 & $8.0 \pm 0.9$ & $8.0 \pm 1.1$ & 0.381 & w \\
\hline T3 & $8.1 \pm 0.9$ & $8.3 \pm 1.0$ & 0.045 & w \\
\hline T4 & $8.1 \pm 0.9$ & $8.4 \pm 1.0$ & 0.001 & w \\
\hline T5 & $8.3 \pm 0.9$ & $8.3 \pm 0.8$ & 0.723 & w \\
\hline T6 & $8.4 \pm 1.0$ & $8.5 \pm 0.9$ & 0.265 & w \\
\hline T7 & $8.8 \pm 0.9$ & $8.7 \pm 1.0$ & 0.326 & w \\
\hline T8 & $9.0 \pm 1.0$ & $9.1 \pm 1.1$ & 0.176 & w \\
\hline T9 & $9.4 \pm 1.1$ & $9.5 \pm 1.1$ & 0.561 & w \\
\hline $\mathrm{T} 10$ & $10.4 \pm 1.2$ & $10.2 \pm 1.0$ & 0.094 & w \\
\hline $\mathrm{T} 11$ & $11.2 \pm 1.1$ & $11.2 \pm 1.2$ & 0.596 & w \\
\hline $\mathrm{T} 12$ & $11.7 \pm 1.1$ & $11.7 \pm 1.1$ & 0.538 & w \\
\hline
\end{tabular}

w Wilcoxon test, SD: Standard deviation. 
T7 to T12. The minimum mean TPD value was $3.8 \mathrm{~mm}$ at T5, whereas the maximum value was $6.2 \mathrm{~mm}$ at T1. When the right and left pedicles were compared, it was observed that, similar to SPD, the values were significantly low on the right T3 and T4 (Table IV). TPD values in $>90 \%$ of the pedicles on the T4 and T5 were smaller than the minimum pedicle diameter $(<5 \mathrm{~mm})$ that is required to insert the minimum screw with adequate stabilization without damaging the pedicle (Table V). Moreover, SPD was not smaller than TPD in any of the vertebrae.

When the correlation of PL, TPD, SPD, and TPA with age, height, and weight was analyzed, no significant correlation was observed between TPA and age, height, and weight in any of the vertebrae (Table $\mathrm{VI}$ ). Moreover, there was no significant correlation between PL and age in any of the vertebrae; however, there was a significant positive correlation between $\mathrm{PL}$ and height in all of the vertebrae and a significant positive correlation between PL and weight in T6-T10 and T12 but not in the remaining vertebrae (Table VII). There was a significant positive correlation between TPD and height in all of the vertebrae except T11-T12. In addition, there was a significant positive correlation between SPD and height in all of the vertebrae excluding T8. However, no significant correlation was observed between TPD and SPD in any of the vertebrae. There was a significant positive correlation between TPD and weight only in T2-T4 and T6 as well as between SPD and weight on T6, T8, T9, and T12 (Table VIII, IX).

When PL, TPD, SPD, and TPA were compared according to sex, it was observed that PL and SPD values were significantly higher in all of the vertebrae in male patients (Table X, XI). TPD values were significantly higher in male patients in all of the vertebrae, excluding T12 (Table XII). TPA values did not reveal

Table IV: Results of Transverse Pedicle Diameter and Comparison Between Right and Left Sides

\begin{tabular}{ccccc}
\hline & Right & Left & & \\
\cline { 1 - 3 } & Mean \pm SD & Mean \pm SD & & \\
\cline { 1 - 3 } T1 & $6.2 \pm 1.0$ & $6.1 \pm 1.0$ & 0.391 & $\mathrm{E}$ \\
\hline T2 & $5.2 \pm 0.9$ & $5.2 \pm 0.9$ & 0.708 & $\mathrm{E}$ \\
\hline T3 & $4.1 \pm 0.7$ & $4.3 \pm 0.8$ & 0.002 & $\mathrm{E}$ \\
\hline T4 & $3.7 \pm 0.8$ & $3.9 \pm 0.64$ & 0.036 & $\mathrm{E}$ \\
\hline T5 & $3.7 \pm 0.8$ & $3.8 \pm 0.7$ & 0.398 & $\mathrm{E}$ \\
\hline T6 & $3.9 \pm 0.8$ & $4.0 \pm 0.8$ & 0.259 & $\mathrm{E}$ \\
\hline T7 & $4.1 \pm 0.8$ & $4.1 \pm 0.8$ & 0.892 & $\mathrm{E}$ \\
\hline T8 & $4.2 \pm 0.8$ & $4.3 \pm 0.9$ & 0.143 & $\mathrm{E}$ \\
\hline T9 & $4.5 \pm 0.8$ & $4.5 \pm 0.9$ & 0.611 & $\mathrm{E}$ \\
\hline T10 & $5.0 \pm 1.1$ & $5.0 \pm 1.1$ & 0.616 & $\mathrm{E}$ \\
\hline T11 & $5.6 \pm 1.2$ & $5.5 \pm 1.2$ & 0.579 & $\mathrm{E}$ \\
\hline T12 & $6.0 \pm 1.0$ & $5.8 \pm 1.1$ & 0.144 & $\mathrm{E}$ \\
\hline Pared & & &
\end{tabular}

E Paired sample t test, SD: Standard deviation. any significant difference in any of the vertebrae between female and male patients (Table XIII).

\section{DISCUSSION}

Although the literature indicates that studies conducted with different populations show significant differences between different countries, there exist significant differences even

Table V: Percentage Less than $5 \mathrm{~mm}$ of Pedicle Transverse Diameter: Right Versus Left

\begin{tabular}{ccccc}
\hline & \multicolumn{2}{c}{ Right } & \multicolumn{2}{c}{ Left } \\
\cline { 2 - 5 } & $\mathbf{n}$ & $\%$ & $\mathbf{n}$ & $\%$ \\
\hline T1 & 6 & 9.5 & 6 & 9.5 \\
\hline T2 & 25 & 39.7 & 27 & 42.9 \\
\hline T3 & 55 & 87.3 & 51 & 81.0 \\
\hline T4 & 60 & 95.2 & 60 & 95.2 \\
\hline T5 & 59 & 93.7 & 59 & 93.7 \\
\hline T6 & 57 & 90.5 & 56 & 88.9 \\
\hline T7 & 55 & 87.3 & 54 & 85.7 \\
\hline T8 & 54 & 85.7 & 51 & 81.0 \\
\hline T9 & 45 & 71.4 & 44 & 69.8 \\
\hline T10 & 35 & 55.6 & 36 & 57.1 \\
\hline T11 & 22 & 34.9 & 22 & 34.9 \\
\hline T12 & 12 & 19.0 & 14 & 22.2 \\
\hline n: Number & & & &
\end{tabular}

n: Number

Table VI: Correlation Between Transverse Pedicle Angle and Age, Height and Weight

\begin{tabular}{|c|c|c|c|c|c|c|}
\hline & \multicolumn{2}{|c|}{ Age } & \multicolumn{2}{|c|}{ Height } & \multicolumn{2}{|c|}{ Weight } \\
\hline & $r$ & $\mathbf{p}$ & $r$ & $p$ & $r$ & $\mathbf{p}$ \\
\hline T1 & -0.028 & 0.825 & -0.096 & 0.475 & 0.038 & 0.778 \\
\hline T2 & -0.075 & 0.558 & 0.085 & 0.525 & -0.058 & 0.666 \\
\hline T3 & 0.027 & 0.835 & 0.211 & 0.113 & -0.011 & 0.936 \\
\hline $\mathbf{T 4}$ & 0.014 & 0.913 & 0.196 & 0.140 & 0.047 & 0.725 \\
\hline T5 & -0.025 & 0.848 & 0.141 & 0.292 & -0.026 & 0.846 \\
\hline T6 & -0.001 & 0.994 & 0.232 & 0.080 & 0.209 & 0.115 \\
\hline T7 & -0.165 & 0.197 & 0.067 & 0.615 & -0.068 & 0.614 \\
\hline T8 & -0.119 & 0.354 & -0.050 & 0.710 & 0.110 & 0.413 \\
\hline T9 & -0.176 & 0.167 & -0.043 & 0.746 & 0.137 & 0.306 \\
\hline T10 & -0.055 & 0.667 & 0.026 & 0.846 & 0.195 & 0.142 \\
\hline T11 & -0.199 & 0.118 & -0.074 & 0.580 & -0.041 & 0.762 \\
\hline T12 & 0.138 & 0.280 & 0.144 & 0.282 & 0.224 & 0.090 \\
\hline
\end{tabular}


within a single country $(5,9)$. The most comprehensive of these studies was conducted on cadaver specimens, and the number of studies that were performed using $\mathrm{CT}$, which is the golden standard in preoperative planning, is limited. There are no studies that were conducted using CT measurements in Turkey. The results from the present study were compared with the most comprehensive studies of the literature that was conducted in different races as well as with the only study by

Table VII: Correlation Between Pedicle Length and Age, Height and Weight

\begin{tabular}{ccccccc}
\hline & \multicolumn{2}{c}{ Age } & \multicolumn{2}{c}{ Height } & \multicolumn{2}{c}{ Weight } \\
\hline & $\mathbf{r}$ & $\mathbf{p}$ & $\mathbf{r}$ & $\mathbf{p}$ & $\mathbf{r}$ & $\mathbf{p}$ \\
\hline T1 & 0.066 & 0.605 & 0.371 & 0.004 & 0.249 & 0.062 \\
\hline T2 & 0.088 & 0.494 & 0.380 & 0.003 & $\mathbf{0 . 0 4 5}$ & 0.738 \\
\hline T3 & $-\mathbf{0 . 0 4 5}$ & 0.728 & 0.389 & 0.003 & 0.129 & 0.335 \\
\hline T4 & $-\mathbf{- 0 . 0 0 8}$ & 0.953 & 0.406 & 0.002 & 0.197 & 0.137 \\
\hline T5 & $\mathbf{- 0 . 0 3 1}$ & 0.807 & 0.340 & 0.009 & 0.147 & 0.270 \\
\hline T6 & $\mathbf{- 0 . 0 8 4}$ & 0.512 & 0.527 & 0.000 & 0.417 & $\mathbf{0 . 0 0 1}$ \\
\hline T7 & $\mathbf{- 0 . 1 1 5}$ & 0.371 & 0.473 & 0.000 & 0.391 & $\mathbf{0 . 0 0 2}$ \\
\hline T8 & $\mathbf{- 0 . 1 4 8}$ & 0.247 & 0.411 & 0.001 & 0.418 & $\mathbf{0 . 0 0 1}$ \\
\hline T9 & $\mathbf{- 0 . 1 0 4}$ & 0.419 & 0.474 & 0.000 & 0.337 & $\mathbf{0 . 0 1 0}$ \\
\hline T10 & $\mathbf{- 0 . 1 0 5}$ & 0.415 & 0.461 & 0.000 & 0.278 & $\mathbf{0 . 0 3 5}$ \\
\hline T11 & $\mathbf{- 0 . 0 2 0}$ & 0.874 & 0.377 & 0.004 & 0.193 & 0.147 \\
\hline T12 & $\mathbf{- 0 . 0 7 0}$ & 0.587 & 0.369 & 0.004 & 0.283 & $\mathbf{0 . 0 3 1}$ \\
\hline & & & & & &
\end{tabular}

Table IX: Correlation Between Transverse Pedicle Diameter and Age, Height and Weight

\begin{tabular}{ccccccc}
\hline & \multicolumn{2}{c}{ Age } & \multicolumn{2}{c}{ Height } & \multicolumn{2}{c}{ Weight } \\
\hline & $\mathbf{r}$ & $\mathbf{p}$ & $\mathbf{r}$ & $\mathbf{p}$ & $\mathbf{r}$ & $\mathbf{p}$ \\
\hline T1 & 0.129 & 0.315 & 0.283 & 0.033 & 0.226 & 0.091 \\
\hline T2 & 0.067 & 0.600 & 0.310 & 0.018 & 0.242 & 0.068 \\
\hline T3 & 0.057 & 0.660 & 0.339 & 0.009 & 0.183 & 0.169 \\
\hline T4 & 0.095 & 0.461 & 0.262 & 0.047 & 0.338 & $\mathbf{0 . 0 1 0}$ \\
\hline T5 & 0.071 & 0.583 & 0.261 & 0.048 & 0.254 & 0.054 \\
\hline T6 & $-\mathbf{0 . 0 0 5}$ & 0.966 & 0.362 & 0.005 & 0.353 & $\mathbf{0 . 0 0 7}$ \\
\hline T7 & 0.094 & 0.465 & 0.264 & 0.045 & 0.216 & 0.103 \\
\hline T8 & $-\mathbf{0 . 0 2 5}$ & 0.847 & 0.292 & 0.026 & 0.360 & $\mathbf{0 . 0 0 6}$ \\
\hline T9 & $-\mathbf{0 . 0 1 5}$ & 0.908 & 0.280 & 0.033 & 0.379 & $\mathbf{0 . 0 0 3}$ \\
\hline T10 & $\mathbf{0 . 0 2 2}$ & 0.863 & 0.283 & 0.031 & 0.265 & $\mathbf{0 . 0 4 5}$ \\
\hline T11 & $-\mathbf{0 . 0 6 0}$ & 0.641 & 0.088 & 0.509 & 0.143 & 0.284 \\
\hline T12 & 0.051 & 0.692 & 0.201 & 0.131 & 0.346 & $\mathbf{0 . 0 0 8}$ \\
\hline & & & & & &
\end{tabular}

Ugur et al. that was performed using cadavers in the Turkish population $(5,9,15,17-23)$. Some of these studies analyze, in a manner similar to our study, all of the vertebrae from T1 to T12, whereas some others analyze certain specific vertebrae, particularly in the lower thoracic region. Furthermore, in some of these studies, all morphological characteristics were examined, whereas in others, only specific morphological characteristics were assessed. Some of these studies were

Table VIII: Correlation Between Sagittal Pedicle Diameter and Age, Height and Weight

\begin{tabular}{ccccccc}
\hline & \multicolumn{2}{c}{ Age } & \multicolumn{2}{c}{ Height } & \multicolumn{2}{c}{ Weight } \\
\hline & $\mathbf{r}$ & $\mathbf{p}$ & $\mathbf{r}$ & $\mathbf{p}$ & $\mathbf{r}$ & $\mathbf{p}$ \\
\hline T1 & $-\mathbf{0 . 1 7 6}$ & 0.168 & 0.292 & 0.027 & 0.224 & 0.094 \\
\hline T2 & $-\mathbf{0 . 0 2 3}$ & 0.860 & 0.424 & 0.001 & 0.311 & $\mathbf{0 . 0 1 7}$ \\
\hline T3 & $-\mathbf{0 . 1 9 1}$ & 0.134 & 0.449 & 0.000 & 0.263 & $\mathbf{0 . 0 4 6}$ \\
\hline T4 & $-\mathbf{- 0 . 1 5 3}$ & 0.231 & 0.302 & 0.021 & 0.277 & $\mathbf{0 . 0 3 5}$ \\
\hline T5 & $-\mathbf{- 0 . 2 1 4}$ & 0.092 & 0.466 & 0.000 & 0.254 & 0.054 \\
\hline T6 & $\mathbf{- 0 . 1 8 8}$ & 0.140 & 0.498 & 0.000 & 0.334 & $\mathbf{0 . 0 1 0}$ \\
\hline T7 & $-\mathbf{- 0 . 1 8 2}$ & 0.154 & 0.362 & 0.005 & 0.243 & 0.066 \\
\hline T8 & $\mathbf{- 0 . 2 0 1}$ & 0.114 & 0.211 & 0.112 & 0.104 & 0.436 \\
\hline T9 & $-\mathbf{- 0 . 2 4 9}$ & 0.049 & 0.278 & 0.034 & $\mathbf{0 . 0 3 6}$ & 0.790 \\
\hline T10 & $\mathbf{- 0 . 3 0 1}$ & 0.017 & 0.297 & 0.023 & $\mathbf{0 . 0 0 0}$ & 0.999 \\
\hline T11 & $\mathbf{- 0 . 1 1 5}$ & 0.368 & 0.405 & 0.002 & $-\mathbf{0 . 0 1 3}$ & 0.925 \\
\hline T12 & $\mathbf{0 . 0 4 7}$ & 0.714 & 0.342 & 0.009 & 0.057 & 0.671 \\
\hline & & & & & &
\end{tabular}

Table X: Comparison of Pedicle Length Between Man and Woman

\begin{tabular}{ccccc}
\hline & Woman & Man & & \\
\cline { 2 - 5 } & Mean \pm SD & Mean \pm SD & p & \\
\hline T1 & $31.4 \pm 3.2$ & $34.7 \pm 3.0$ & $\mathbf{0 . 0 0 0}$ & ${ }^{\mathrm{t}}$ \\
\hline T2 & $32.6 \pm 2.9$ & $36.5 \pm 3.5$ & $\mathbf{0 . 0 0 0}$ & ${ }^{\mathrm{t}}$ \\
\hline T3 & $33.4 \pm 3.4$ & $36.8 \pm 3.0$ & $\mathbf{0 . 0 0 0}$ & ${ }^{\mathrm{t}}$ \\
\hline T4 & $33.8 \pm 2.4$ & $37.1 \pm 3.3$ & $\mathbf{0 . 0 0 0}$ & ${ }^{\mathrm{t}}$ \\
\hline T5 & $34.9 \pm 2.1$ & $38.1 \pm 2.8$ & $\mathbf{0 . 0 0 0}$ & ${ }^{\mathrm{t}}$ \\
\hline T6 & $34.7 \pm 1.6$ & $38.8 \pm 2.5$ & $\mathbf{0 . 0 0 0}$ & ${ }^{\mathrm{t}}$ \\
\hline T7 & $35.6 \pm 1.9$ & $39.6 \pm 2.3$ & $\mathbf{0 . 0 0 0}$ & ${ }^{\mathrm{t}}$ \\
\hline T8 & $36.9 \pm 1.7$ & $40.7 \pm 2.4$ & $\mathbf{0 . 0 0 0}$ & ${ }^{\mathrm{t}}$ \\
\hline T9 & $37.0 \pm 2.0$ & $41.1 \pm 2.6$ & $\mathbf{0 . 0 0 0}$ & ${ }^{\mathrm{t}}$ \\
\hline T10 & $36.7 \pm 1.7$ & $41.3 \pm 2.7$ & $\mathbf{0 . 0 0 0}$ & ${ }^{\mathrm{t}}$ \\
\hline T11 & $36.6 \pm 1.8$ & $40.7 \pm 2.8$ & $\mathbf{0 . 0 0 0}$ & ${ }^{\mathrm{t}}$ \\
\hline T12 & $36.7 \pm 2.5$ & $40.0 \pm 3.1$ & $\mathbf{0 . 0 0 0}$ & ${ }^{\mathrm{t}}$ \\
\hline
\end{tabular}

${ }^{t} t$ test, SD: Standard deviation. 
Table XI: Comparison of Sagittal Pedicle Diameter Between Man and Woman

\begin{tabular}{cccccc}
\hline & Woman & Man & & \\
\cline { 2 - 3 } & Mean \pm SD & Mean \pm SD & & \\
\hline T1 & $6.5 \pm 0.7$ & $7.5 \pm 0.8$ & $\mathbf{0 . 0 0 0}$ & $\mathrm{m}$ \\
\hline T2 & $7.2 \pm 0.7$ & $8.3 \pm 0.8$ & $\mathbf{0 . 0 0 0}$ & $\mathrm{m}$ \\
\hline T3 & $7.5 \pm 0.6$ & $8.5 \pm 0.8$ & $\mathbf{0 . 0 0 0}$ & $\mathrm{m}$ \\
\hline T4 & $7.6 \pm 0.7$ & $8.6 \pm 0.8$ & $\mathbf{0 . 0 0 0}$ & $\mathrm{m}$ \\
\hline T5 & $7.6 \pm 0.6$ & $8.6 \pm 0.7$ & $\mathbf{0 . 0 0 0}$ & $\mathrm{m}$ \\
\hline T6 & $7.6 \pm 0.5$ & $8.8 \pm 0.8$ & $\mathbf{0 . 0 0 0}$ & $\mathrm{m}$ \\
\hline T7 & $8.0 \pm 0.7$ & $9.1 \pm 0.7$ & $\mathbf{0 . 0 0 0}$ & $\mathrm{m}$ \\
\hline T8 & $8.4 \pm 0.7$ & $9.4 \pm 0.9$ & $\mathbf{0 . 0 0 0}$ & $\mathrm{m}$ \\
\hline T9 & $8.8 \pm 1.0$ & $9.7 \pm 0.9$ & $\mathbf{0 . 0 0 2}$ & $\mathrm{m}$ \\
\hline T10 & $9.5 \pm 0.9$ & $10.7 \pm 0.9$ & $\mathbf{0 . 0 0 0}$ & $\mathrm{m}$ \\
\hline T11 & $10.6 \pm 1.1$ & $11.5 \pm 0.9$ & $\mathbf{0 . 0 0 1}$ & $\mathrm{m}$ \\
\hline T12 & $11.1 \pm 1.1$ & $11.9 \pm 1.0$ & $\mathbf{0 . 0 0 3}$ & $\mathrm{m}$ \\
\hline
\end{tabular}

mMann-whitney u test, SD: Standard deviation.

Table XIII: Comparison of Transverse Pedicle Angle Between Man and Woman

\begin{tabular}{ccccc}
\hline & Woman & Man & p & \\
\cline { 2 - 3 } & Mean \pm SD & Mean \pm SD & & \\
\hline T1 & $34.1 \pm 6.5$ & $33.4 \pm 5.5$ & 0.564 & $\mathrm{~m}$ \\
\hline T2 & $22.4 \pm 5.8$ & $21.6 \pm 5.4$ & 0.626 & $\mathrm{~m}$ \\
\hline T3 & $15.3 \pm 4.7$ & $13.9 \pm 4.1$ & 0.337 & $\mathrm{~m}$ \\
\hline T4 & $11.4 \pm 2.5$ & $10.7 \pm 2.6$ & 0.224 & $\mathrm{~m}$ \\
\hline T5 & $9.9 \pm 2.0$ & $9.8 \pm 2.5$ & 0.498 & $\mathrm{~m}$ \\
\hline T6 & $9.2 \pm 2.3$ & $9.4 \pm 2.4$ & 0.735 & $\mathrm{~m}$ \\
\hline T7 & $8.8 \pm 1.6$ & $8.2 \pm 1.9$ & 0.456 & $\mathrm{~m}$ \\
\hline T8 & $8.8 \pm 2.3$ & $8.4 \pm 2.3$ & 0.588 & $\mathrm{~m}$ \\
\hline T9 & $8.6 \pm 2.0$ & $7.9 \pm 2.0$ & 0.321 & $\mathrm{~m}$ \\
\hline T10 & $7.6 \pm 2.0$ & $6.9 \pm 1.8$ & 0.148 & $\mathrm{~m}$ \\
\hline T11 & $4.8 \pm 1.8$ & $4.6 \pm 1.7$ & 0.775 & $\mathrm{~m}$ \\
\hline T12 & $2.9 \pm 1.9$ & $2.7 \pm 1.5$ & 0.916 & $\mathrm{~m}$ \\
\hline
\end{tabular}

mMann-whitney u test, SD: Standard deviation.

conducted on cadavers, whereas others were based on CT measurements. All this information is presented in detail in the tables.

The stability of a pedicle screw is directly proportional to its length and width, and the minimum screw diameter that is clinically approved is $4 \mathrm{~mm}$. When $1 \mathrm{~mm}$ of clearance is added to this diameter, the minimum pedicle diameter should
Table XII: Comparison of Transverse Pedicle Diameter Between Man and Woman

\begin{tabular}{|c|c|c|c|c|}
\hline & Woman & Man & \multirow{2}{*}{$\mathbf{p}$} & \\
\hline & Mean \pm SD & Mean \pm SD & & \\
\hline $\mathbf{T 1}$ & $5.6 \pm 1.0$ & $6.4 \pm 0.8$ & 0.002 & $t$ \\
\hline T2 & $4.6 \pm 0.8$ & $5.5 \pm 0.7$ & 0.000 & $\mathrm{t}$ \\
\hline T3 & $3.7 \pm 0.6$ & $4.4 \pm 0.6$ & 0.000 & $t$ \\
\hline T4 & $3.3 \pm 0.6$ & $4.0 \pm 0.6$ & 0.001 & $\mathrm{t}$ \\
\hline T5 & $3.4 \pm 0.7$ & $3.9 \pm 0.7$ & 0.006 & $\mathrm{t}$ \\
\hline T6 & $3.4 \pm 0.6$ & $4.2 \pm 0.6$ & 0.000 & $\mathrm{t}$ \\
\hline $\mathrm{T7}$ & $3.7 \pm 0.8$ & $4.3 \pm 0.7$ & 0.003 & $\mathrm{t}$ \\
\hline T8 & $3.7 \pm 0.7$ & $4.5 \pm 0.7$ & 0.000 & $\mathrm{t}$ \\
\hline T9 & $4.1 \pm 0.8$ & $4.7 \pm 0.7$ & 0.001 & $\mathrm{t}$ \\
\hline T10 & $4.5 \pm 1.0$ & $5.2 \pm 1.0$ & 0.011 & $\mathrm{t}$ \\
\hline T11 & $5.1 \pm 0.8$ & $5.7 \pm 1.2$ & 0.044 & $\mathrm{t}$ \\
\hline T12 & $5.6 \pm 1.0$ & $6.0 \pm 0.9$ & 0.154 & $t$ \\
\hline
\end{tabular}

${ }^{t}$ ttest, SD: Standard deviation.

be $5 \mathrm{~mm}$ to ensure that the screw with the minimum diameter and adequate stabilization is inserted without damaging the pedicle (16). The decisive factor that will determine the optimal maximum width of a screw is the pedicle's diameter on horizontal and sagittal planes, which cannot be estimated or measured at the time of the operation. In the present study, SPD value exhibits a similar trend with the other studies in the literature; however, this value is lower at all levels than other studies in the literature $(3,5,17,23,25)$ (Table XIV). It gradually increases from $\mathrm{T} 1$ toward the distal vertebrae, reaching the maximum value at T12. Consistent with the findings of most of the studies in the literature, SPD value is higher than TPD value at all levels in our study. Therefore, SPD is not a restricting parameter for screw width. The optimal screw diameter should be measured based on TPD. In our study, TPD is greater in the proximal and distal regions and is smaller in the midthoracic region. The lowest value of TPD was $3.8 \mathrm{~mm}$ on the T4 and T5 vertebrae. Moreover, in $>90 \%$ of the pedicles at these levels, the pedicle width was $<5 \mathrm{~mm}$ and the minimum pedicle width was measured as $2.2 \mathrm{~mm}$. Similar to other studies of the literature, TPD was greater in the proximal and distal regions and smaller in the midthoracic region. Compared with the results from the studies conducted based on CT scans, the results from our study reveal that TPD is smaller than the ones in other studies, except the study of Datir and Mitra, at almost all levels $(1,2,5,9,13,26)$. Compared with the result from the studies conducted on cadavers, it is smaller than the ones in all of the other studies including the study by Ugur et al. $(3,17,23,25)$. Compared with the study by Ugur et al., the mean TPD value was $<1.1 \mathrm{~mm}$ at all levels (Table XV). In their study, Datir and Mitra compared the direct measurements of vertebrae and the values obtained by CT measurements and 


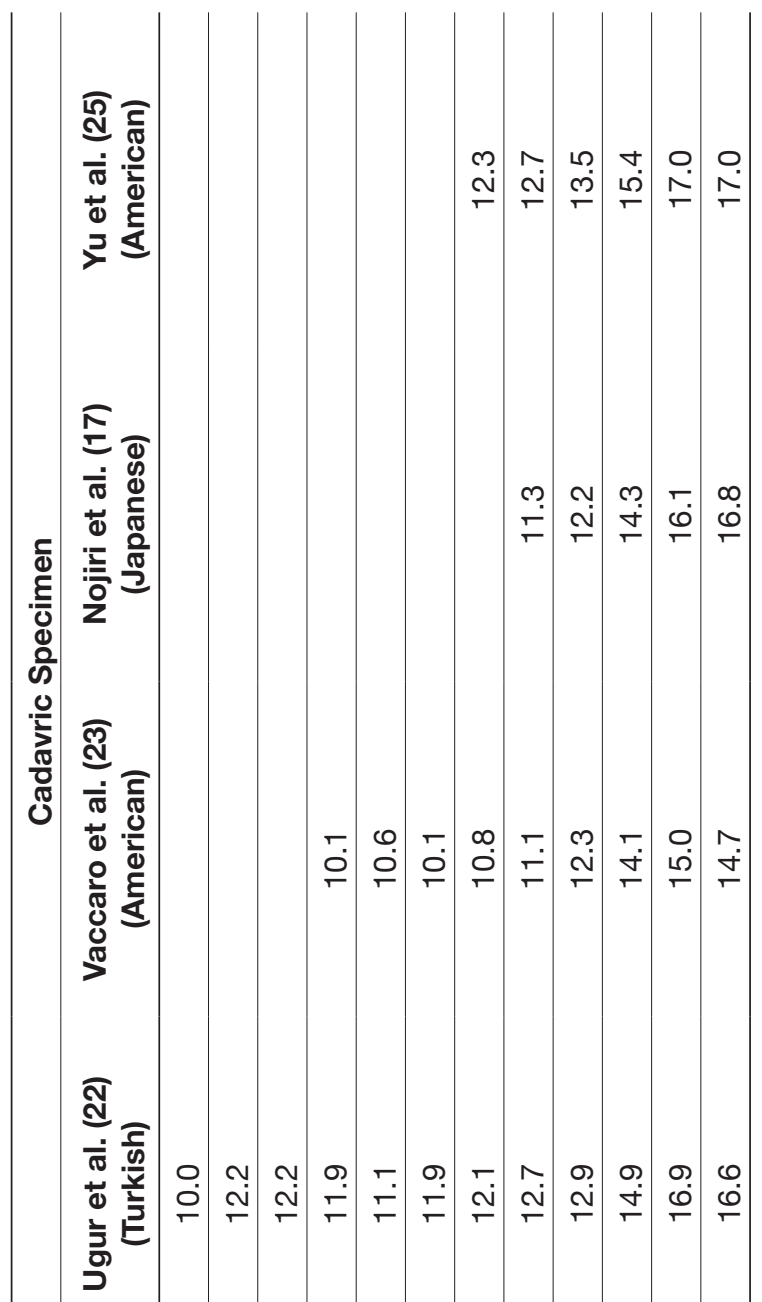

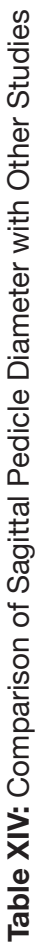

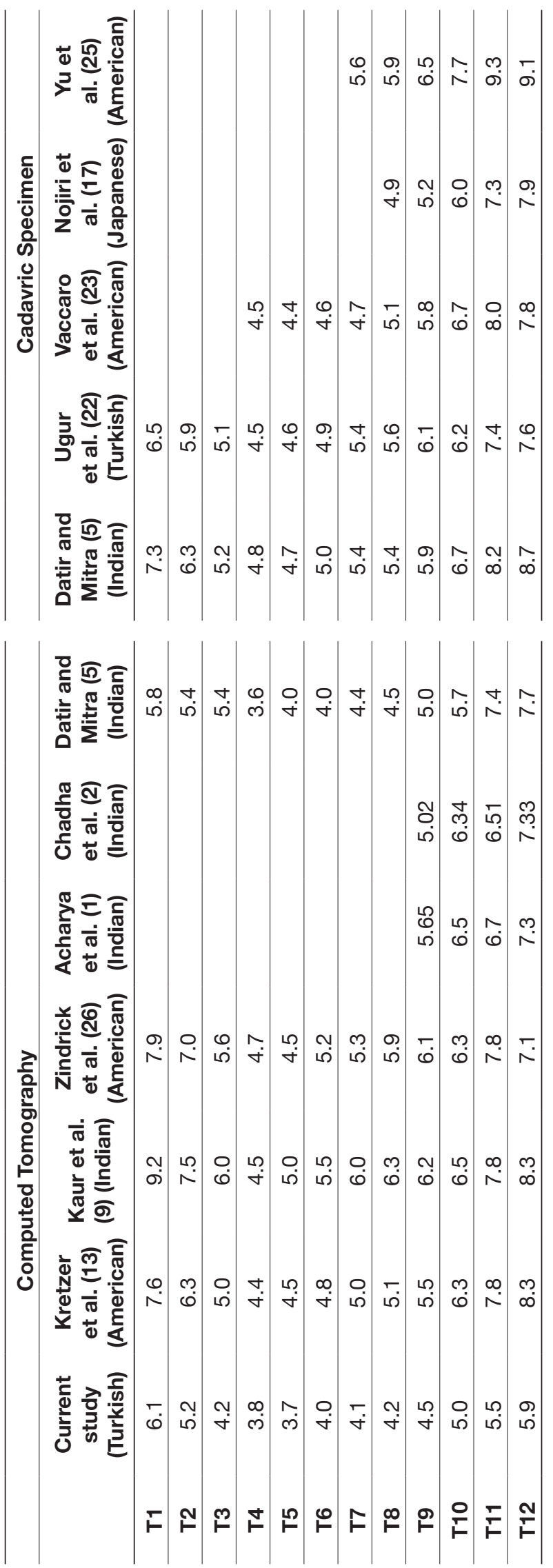


concluded that the values obtained by CT measurements are significantly smaller, which is caused by the measurements of the convex-shaped pedicles made on transverse planes on the CT, according to them (5). We agree that the reason for the higher values observed in the study by Ugur et al. is the same as stated above. On comparing the right and left pedicles in terms of TPD, the TPD values only in the right T3 and T4 were observed to be slightly yet significantly lower (Table IV). In conclusion, the use of a 4-mm screw that is recognized reliable in terms of biomechanics, particularly between T3 and T9, might result in overflow outside the pedicle. Kretzer et al. suggested that in cases where in the pedicles are unsuitable for screw placement because of small TPD value, that segment should be skipped and a hook should be used or the pedicle should be inserted using the in-out-in technique (Figure 2) (13). Moreover, we suggest that the pedicles between T3 and T9 be measured during the preoperative period and an approach be planned preoperatively as well as that the vertebrae with thin pedicles be skipped or the screw be inserted using the in-out-in technique. It is our conviction that screws of $5-\mathrm{mm}$ diameters can securely be used for $\mathrm{T} 1, \mathrm{~T} 2$, $\mathrm{T} 11$, and $\mathrm{T} 12$, and that the midthoracic region requires high level of attention even when using a screw of 4-mm diameter.

The differences in TPA are the most evident differences when the morphological characteristics of the thoracic vertebral pedicles are compared by race in literature. The mean TPA has the highest value of $33.6^{\circ}$ at $\mathrm{T} 1$ and diminishes toward the distal vertebrae, and its minimum value is $2.8^{\circ}$ at $\mathrm{T} 12$. Our results are higher than those obtained in the study by Datir and Mitra (5). However, they are similar to those obtained in the studies by Kretzer et al. and Zindrick et al. $(13,26)$. Although anterolateral angling is observed at T11 and T12 in the studies conducted by Kretzer et al., Kim et al, and Kaur et al, in our study and in studies by Vaccaro et al. Datir and Mitra and Zindrick et al., the lowest TPA was 0; however, no lateral angling was observed $(5,9,10,13,23,26)$ (Table XVI). This reduction in medial angling is crucial for medial perforation risk. Moreover, vascular damage and cord damage risk is high in the event of medial perforation because the spinal canal is relatively narrow in the thoracic region (1). Comparing the right and left pedicles, Kretzer et al. observed a small but significant increase in the TPA of the left pedicles at the levels between T3 and T12 that are associated with the medialization of the aorta in this region (13). However, in other studies, no significant difference was observed. The results of the present study are similar to those obtained in the study of Kretzer et al. TPA significantly increased in the left pedicles at the levels between T3-T8 (Table I). These results reveal that while inserting a pedicle screw in the thoracic region, it should be considered that the thoracic vertebral pedicle medial angling is smaller in the Turkish population compared with other population and that the angling is higher on the left pedicles between the levels T3-T8.

The PL gradually increases from $\mathrm{T} 1$ toward $\mathrm{T} 10$, and decreases from T10 toward T12. This decrease in the ultimate two vertebral pedicles is expected considering the decrease in TPA. The shortest PL is $26.7 \mathrm{~mm}$ at T1, whereas the longest is $48.5 \mathrm{~mm}$ at T11. Compared with the other studies in the

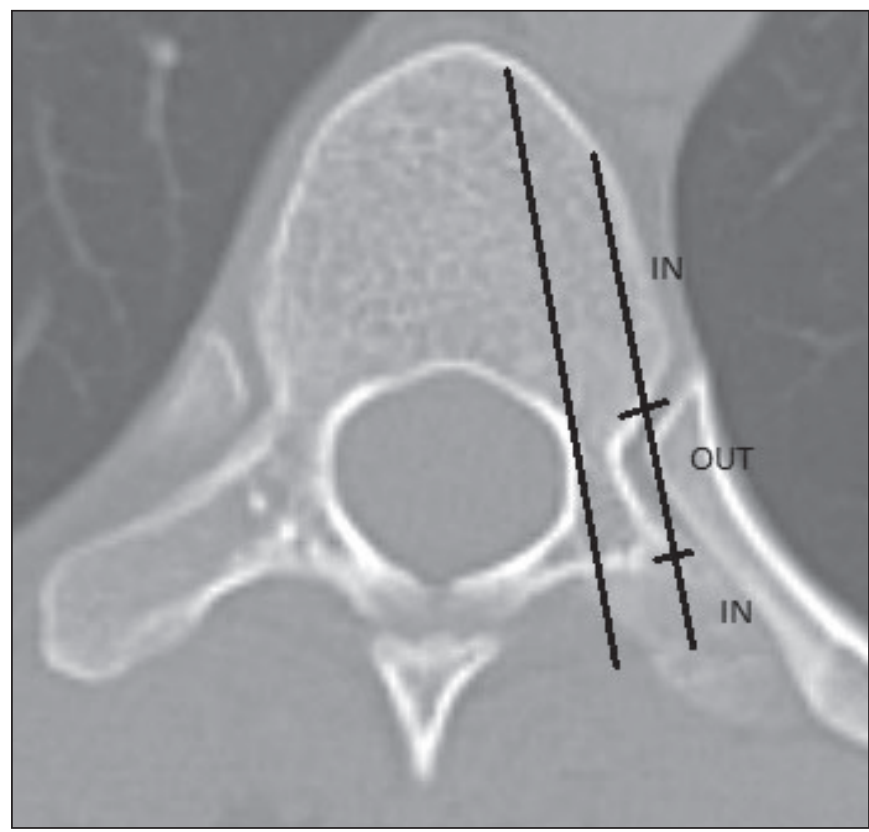

Figure 2: Diagram depicting the "in-out-in" technique of pedicle screw placement in a narrow pedicle diameter.

literature, the PL at all levels were shorter compared with Kretzer et al. Zindrick et al. and Vaccaro et al. $(13,23,26)$. According to the study by Datir and Mitra, PL was higher in all of the levels except T12 and T9 (5). According to Kaur et al., it was higher at T4-T8 and T10 and shorter at the remaining levels. Compared with the study conducted by Acharya et al. and Chadha et al. to examine the lower thoracic region, it was shorter at T9 and 10 and higher at T11 and T12 $(1,2)$. Compared with the study by Nojiri et al. examining the levels between T8-T12, the results from our study were higher than those from that study at all levels (Table XVII) (17). According to these results, compared with other studies in the literature, there exist significant differences in different populations. We believe that the maximum length of screw to be used in the thoracic region is $45 \mathrm{~mm}$ and that it should be $25-30 \mathrm{~mm}$ long for the upper thoracic region and $30-45 \mathrm{~mm}$ long for the midand lower thoracic regions.

In terms of the effects of the demographical characteristics, Kretzer et al., in their study comparing the PLs by sex, revealed that the mean $\mathrm{PL}$ is $4 \mathrm{~mm}$ longer and the TPD is $1.4 \mathrm{~mm}$ wider in male patients at all levels (13). In another study that compared TPD by sex, Kim et al. observed that TPD is wider in male patients, although this difference was significant only at T10 (10). The most comprehensive study that focused on the effects of the demographic characteristics on PLs was conducted by Yu et al., which divided patients into groups by age, height, and weight to compare their pedicle characteristics (25). This study revealed that TPD and SPD increase in line with age, weight, and height. The study by Nojiri et al. revealed that male patients have wider pedicles; however, there was no correlation between pedicle angle and sex and age does not exhibit any correlation with any of the pedicle characteristics (17). In our study, we observed 
that PL exhibits a significant increase in certain segments in correlation with weight and in all segments in correlation with height. Moreover, TPD and SPD increased in correlation with height at all segments, whereas these parameters increased in certain segments in correlation with weight (Table VIII, IX). Differently from the study of Yu et al., (25) no correlation was found between age and PL, TPD, and SPD. TPA was not affected by age, height, and sex, whereas TPD, SPD, and PL are all significantly higher in male patients at all levels (Table VI, VII, VIII, IX). In summary, independently from the age factor, long and wide screws are expected to be required for male patients who are taller.

Table XVI: Comparison of Transverse Pedicle Angle with Other Studies

\begin{tabular}{|c|c|c|c|c|c|c|c|c|}
\hline \multicolumn{8}{|c|}{ Computed Tomography } & \multirow{2}{*}{$\begin{array}{l}\text { Cadavric Specimen } \\
\text { Vaccaro et al. (23) } \\
\text { (American) }\end{array}$} \\
\hline & $\begin{array}{c}\text { Current } \\
\text { study } \\
\text { (Turkish) }\end{array}$ & $\begin{array}{c}\text { Kretzer } \\
\text { et al. (13) } \\
\text { (American) }\end{array}$ & $\begin{array}{l}\text { Kaur et al. (9) } \\
\text { (Indian) }\end{array}$ & $\begin{array}{c}\text { Zindrick } \\
\text { et al. (26) } \\
\text { (American) }\end{array}$ & $\begin{array}{l}\text { Acharya } \\
\text { et al. (1) } \\
\text { (Indian) }\end{array}$ & $\begin{array}{l}\text { Chadha et al. } \\
\text { (2) (Indian) }\end{array}$ & $\begin{array}{l}\text { Datir and } \\
\text { Mitra (5) } \\
\text { (Indian) }\end{array}$ & \\
\hline T1 & 33.6 & 32.8 & 35.4 & 27.0 & & & 27.0 & \\
\hline T2 & 21.85 & 20.5 & 26.2 & 20.0 & & & 18.0 & \\
\hline T3 & 14.3 & 13.5 & 20.0 & 15.0 & & & 10.0 & \\
\hline T4 & 10.9 & 11.0 & 19.0 & 13.0 & & & 7.0 & 44.1 \\
\hline T5 & 9.8 & 9.9 & 16.0 & 9.0 & & & 5.0 & 39.3 \\
\hline T6 & 9.3 & 8.7 & 14.3 & 10.0 & & & 5.0 & 38.9 \\
\hline T7 & 8.4 & 8.3 & 11.8 & 9.0 & & & 4.0 & 43.6 \\
\hline T8 & 8.5 & 8.9 & 12.2 & 8.0 & & & 2.0 & 44.7 \\
\hline T9 & 8.1 & 9.8 & 11.2 & 8.0 & 7.22 & 5.42 & 2.0 & 43.5 \\
\hline T10 & 7.1 & 8.3 & 8.7 & 5.0 & -19.49 & 5.16 & 3.0 & 44.1 \\
\hline $\mathrm{T} 11$ & 4.6 & 5.9 & -2.3 & 1.0 & -10.59 & -2.97 & 0.0 & 40.8 \\
\hline T12 & 2.8 & 3.8 & -9.8 & 4.0 & -10.69 & -3.00 & 0.0 & 46.6 \\
\hline
\end{tabular}

Table XVII: Comparison of Pedicle Length with Other Studies

Computed Tomography

\begin{tabular}{|c|c|c|c|c|c|c|c|c|c|c|}
\hline & $\begin{array}{l}\text { Current } \\
\text { study } \\
\text { (Turkish) }\end{array}$ & $\begin{array}{c}\text { Kretzer } \\
\text { et al. (13) } \\
\text { (American) }\end{array}$ & $\begin{array}{l}\text { Kaur et al. } \\
\text { (9) (Indian) }\end{array}$ & $\begin{array}{c}\text { Zindrick } \\
\text { et al. (26) } \\
\text { (American) }\end{array}$ & $\begin{array}{l}\text { Acharya } \\
\text { et al. (1) } \\
\text { (Indian) }\end{array}$ & $\begin{array}{l}\text { Chadha } \\
\text { et al. (2) } \\
\text { (Indian) }\end{array}$ & $\begin{array}{c}\text { Datir and } \\
\text { Mitra (5) } \\
\text { (Indian) }\end{array}$ & $\begin{array}{l}\text { Datir and } \\
\text { Mitra (5) } \\
\text { (Indian) }\end{array}$ & $\begin{array}{c}\text { Vaccaro } \\
\text { et al. (23) } \\
\text { (American) }\end{array}$ & $\begin{array}{c}\text { Nojiri } \\
\text { et al. (17) } \\
\text { (Japanese) }\end{array}$ \\
\hline T1 & 33.7 & 33.9 & 30.3 & 36.9 & & & 31.1 & 29.9 & & \\
\hline T2 & 35.3 & 35.3 & 32.3 & 35.7 & & & 31.0 & 29.9 & & \\
\hline T3 & 35.7 & 36.6 & 33.2 & 37.7 & & & 28.8 & 30.3 & & \\
\hline T4 & 36.0 & 38.4 & 36.5 & 38.5 & & & 31.8 & 31.7 & 44.1 & \\
\hline T5 & 37.1 & 39.6 & 37.8 & 41.9 & & & 34.7 & 33.7 & 39.3 & \\
\hline T6 & 37.5 & 40.6 & 39.8 & 42.1 & & & 36.1 & 34.8 & 38.9 & \\
\hline T7 & 38.3 & 42.0 & 40.0 & 42.6 & & & 36.8 & 34.4 & 43.6 & \\
\hline T8 & 39.5 & 43.4 & 40.6 & 45.4 & & & 39.8 & 34.7 & 44.7 & 37.4 \\
\hline T9 & 39.8 & 44.9 & 39.5 & 45.2 & 40.85 & 42.27 & 40.6 & 35.5 & 43.5 & 37.8 \\
\hline T10 & 39.9 & 44.4 & 40.1 & 44.0 & 42.71 & 43.47 & 38.8 & 36.0 & 44.1 & 37.8 \\
\hline $\mathrm{T} 11$ & 39.4 & 43.9 & 36.2 & 41.8 & 34.43 & 35.14 & 38.6 & 37.3 & 40.8 & 37.8 \\
\hline T12 & 39.0 & 44.5 & 34.2 & 38.6 & 34.43 & 34.73 & 40.1 & 34.7 & 46.6 & 38.8 \\
\hline
\end{tabular}


There are certain limitations in our study. Despite studies that conclude that there are no differences between the CTbased and cadaver-based measurements in the literature, there are also certain studies that reveal that the CT-based measurements result in lower values than the ones conducted on cadavers $(5,18)$. Human pedicle is not completely cylindrical in shape, and considering the physiological thoracic kyphoses, CT planes on axial plane are not in parallel with the pedicle axis (Figure 3). Therefore, it is an expected result that the measurements are smaller than they actually are. Moreover, the use of 4-mm cut section in tomographic scanning can be considered as another limitation. However, according to Kaur et al., there are no significant difference between his study that used the 4-mm cut section and those conducted by Datir and Mitra and Shetty et al. using $5-\mathrm{mm}$ cut section and by Acharya et al. and Chadha et al. using 3-mm cut section $(1,2,5,9,21)$.

\section{CONCLUSION}

There are significant variations based on the physical characteristics of the population where the study was conducted in terms of the morphological characteristics of their pedicle. Compared with other populations, the Turkish population has a smaller pedicle width on sagittal and transverse planes, and their PL and medial angling is similar to those of other populations. Male patients who are taller and overweight have higher pedicle width and length. Because the assessment made using CT measurements provided smaller values compared with the ones conducted on cadavers, it is a secure method for preoperative planning. The midthoracic region in particular should be assessed based on CT scans preoperatively and salvage procedures should be considered.

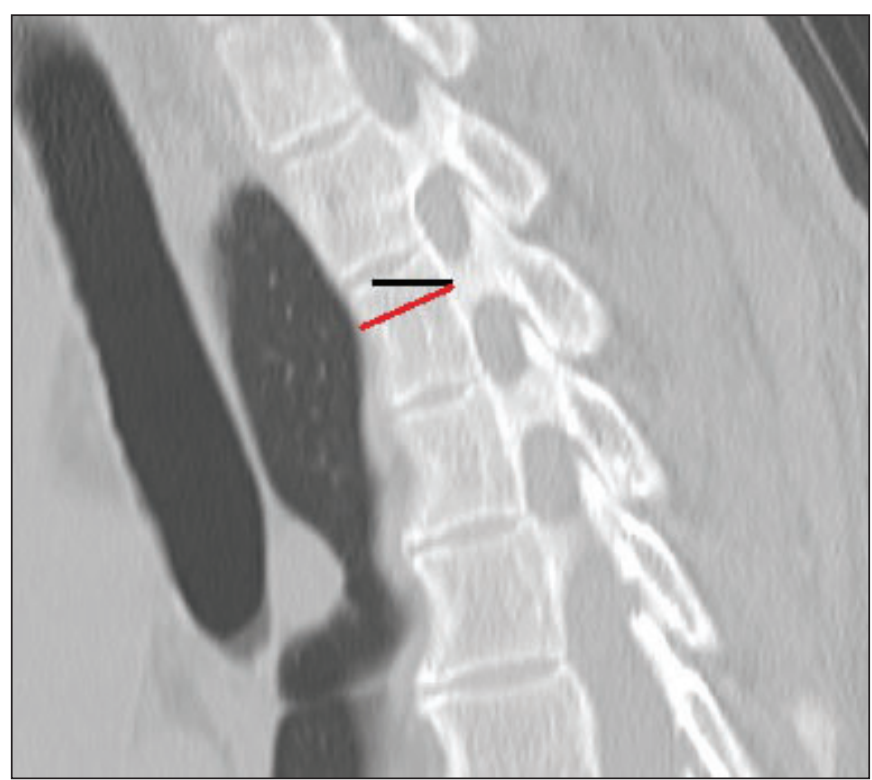

Figure 3: Red line depicting the direction of pedicle and the black line depicting the direction of computed tomography (CT) section.

\section{REFERENCES}

1. Acharya S, Dorje T, Srivastava A: Lower dorsal and lumbar pedicle morphometry in Indian population: A study of four hundred fifty vertebrae. Spine 35:378-384, 2010

2. Chadha M, Balain B, Maini L, Dhaon BK: Pedicle morphology of the lower thoracic, lumbar, and S1 vertebrae: An Indian perspective. Spine 28:744-749, 2003

3. Chaynes P, Sol JC, Vaysse P, Bécue J, Lagarrigue J: Vertebral pedicle anatomy in relation to pedicle screw fixation: A cadaver study. Surg Radiol Anat 23:85-90, 2001

4. Cinotti G, Gumina S, Ripani M, Postacchini F: Pedicle instrumentation in the thoracic spine. A morphometric and cadaveric study for placement of screws. Spine 24:114-119, 1999

5. Datir SP, Mitra SR: Morphometric study of the thoracic vertebral pedicle in an Indian population. Spine 29:11741181, 2004

6. Ebraheim NA, Jabaly G, Xu R, Yeasting RA: Anatomic relations of the thoracic pedicle to the adjacent neural structures. Spine 22:1553-1556, 1997

7. Gulec A, Kacira BK, Kutahya H, Ozbiner H, Ozturk M, Solbas CS, Gokmen IE: Morphometric analysis of the lumbar vertebrae in the Turkish population using three-dimensional computed tomography: Correlation with sex, age, and height. Folia Morphol 76:433-439, 2017

8. Karaikovic EE, Daubs MD, Madsen RW, Gaines RW Jr: Morphologic characteristics of human cervical pedicles. Spine 22:493-500,1997

9. Kaur K, Singh R, Prasath V, Magu S, Tanwar M: Computed tomographic-based morphometric study of thoracic spine and its relevance to anaesthetic and spinal surgical procedures. J Clin Orthop Trauma 7:101-108, 2016

10. Kim KD, Patrick Johnson J, Bloch BS O, Masciopinto JE: Computer-assisted thoracic pedicle screw placement: An in vitro feasibility study. Spine 26:360-364, 2001

11. Kotani Y, Cunningham BW, Abumi K, McAfee PC: Biomechanical analysis of cervical stabilization systems. An assessment of transpedicular screw fixation in the cervical spine. Spine 19:2529-2539, 1994

12. Krag MH, Weaver DL, Beynnon BD, Haugh LD: Morphometry of the thoracic and lumbar spine related to transpedicular screw placement for surgical spinal fixation. Morphometry of the thoracic and lumbar spine related to transpedicular screw placement for surgical spinal fixation. Spine 13:27-32, 1988

13. Kretzer RM, Chaput C, Sciubba DM, Garonzik IM, Jallo GI, McAfee PC, Cunningham BW, Tortolani PJ: A computed tomography-based morphometric study of thoracic pedicle anatomy in a random United States trauma population. J Neurosurg Spine 14:235-243, 2011

14. Magerl FP: Stabilization of the lower thoracic and lumbar spine with external skeletal fixation. Clin Orthop Relat Res 189:125-141, 1984

15. McLain RF, Ferrara L, Kabins M: Pedicle morphometry in the upper thoracic spine: Limits to safe screw placement in older patients. Spine 27:2467-2471, 2002 
Demiroz S. and Erdem S: Morphometric Analysis of Pedicles

16. Misenhimer GR, Peek RD, Wiltse LL, Rothman SL, Widell EH Jr: Anatomic analysis of pedicle cortical and cancellous diameter as relatedtoscrew size. Spine 14:367-372, 1989

17. Nojiri K, Matsumoto M, Chiba K, Toyama Y: Morphometric analysis of the thoracic and lumbar spine in Japanese on the use of pedicle screws. Surg Radiol Anat 27:123-128, 2005

18. Pai BS Gangadhara, Nirmala S, Muralimohan S, Varsha SM: Morphometric analysis of the thoracic pedicle: An anatomicoradiological study. Neurol India 58:253-258, 2010

19. Sengul G, Kadioglu HH: Morphometric anatomy of the atlas and axis vertebrae. Turk Neurosurg 16:69-76, 2006

20. Senoğlu M, Ozbağ D, Gümüşalan Y: C2 intralaminar screw placement: A quantitative an atomical and morphometric evaluation. Turk Neurosurg 19:245-248, 2009

21. Shetty AS, Avadhani R, Mahesha B, Shantaram M: Pedicle morphometry: A radiological assessment using computerized tomographic (CT) scan. Int J Basic Appl Med Sci 1:23-25, 2011
22. Ugur HC, Attar A, Uz A, Tekdemir I, Egemen N, Genc Y: Thoracic pedicle: Surgical anatomic evaluation and relations. J Spinal Disord 14:39-45, 2001

23. Vaccaro AR, Rizzolo SJ, Allardyce TJ, Ramsey M, Salvo J, Balderston RA, Cotler JM: Lacement of pediclescrews in thethoracicspine. Part I: Morphometric analysis of the thoracic vertebrae. J Bone Joint Surg Am 77:1193-1199, 1995

24. Xu R, Ebraheim NA, Ou Y, Yeasting RA: Anatomic considerations of pedicle screw placement in the thoracic spine. Roy-Camille technique versus open-lamina technique. Spine 23:1065-1068, 1998

25. Yu CC, Yuh RT, Bajwa NS, Toy JO, Ahn UM, Ahn NU: Lower thoracic pedicle morphometry: Male, taller, and heavier specimens have bigger pedicles. Spine 40:323-331, 2015

26. Zindrick MR, Wiltse LL, Doornik A, Widell EH, Knight GW, Patwardhan AG, Thomas JC, Rothman SL, Fields BT: Analysis of the morphometric characteristics of the thoracic and lumbar pedicles. Spine 12:160-166, 1987 